\title{
TEMPO DE TRABALHO E IMATERIALIDADE NA TEORIA SOCIAL DE ANDRÉ GORZ
}

\author{
Josué Pereira da Silva*
}

\begin{abstract}
O artigo trata das formulações de André Gorz sobre trabalho imaterial. Sua análise do capitalismo contemporâneo se baseia num modelo formado pelas categorias conhecimento, valor e capital, no qual conhecimento é a força produtiva principal. Este artigo contrapõe esse modelo a um modelo anterior, formado pelas categorias trabalho, valor e capital, no qual trabalho é a força produtiva principal; realça que a diferença entre os dois está na substituição de trabalho por conhecimento. Numa economia do conhecimento, como a do primeiro modelo, a produtividade da maior parte das atividades não se presta a ser medida pelo tempo de trabalho, como no capitalismo clássico; além disso, muitas delas dependem de saberes práticos que não se prestam a ser codificados e apropriados privadamente. A tese aqui defendida é de que o principal evento por trás da mudanca de um modelo a outro é a diluição do tempo de trabalho como critério para medir a produtividade; e isso afeta a teoria do valor e, portanto, a base de cálculo das equivalências pelo capitalismo. Essa é, segundo Gorz, a principal causa da crise do capitalismo e do trabalho assalariado como critério para a atribuição de direitos; e isso é também motivo suficiente para que ele passe a defender a transferência incondicional de renda para as pessoas.

Palavras-chave: André Gorz. Conhecimento. Trabalho imaterial. Tempo de trabalho. Teoria do valor. Crise do capitalismo.
\end{abstract}

A substituição de trabalho vivo por trabalho objetivado [...] é o último desenvolvimento da relação de valor e da produção com base no valor. Sua pressuposição é, e continua sendo, o volume puro do tempo de trabalho imediato, a quantidade de trabalho empregada, como fator decisivo na produção de riqueza. Mas, na medida em que a grande indústria se desenvolve, a criação de riqueza real torna-se cada vez menos dependente do tempo de trabalho e da quantidade de trabalho empregada que do poder dos agentes colocados em movimento durante o tempo de trabalho [...]. Uma vez ocorrida essa transformação, não é mais o trabalho imediato exercido pelo próprio homem, nem o tempo durante o qual ele trabalha, mas é a apropriação de seu próprio poder produtivo geral, sua compreensão e dominação da Natureza, em virtude de ele ser uma entidade social - em uma palavra, o desenvolvimento do indivíduo social - que aparece como a pedra fundamental da produção e da riqueza [...]. Tão logo o trabalho em sua forma imediata deixa de ser a fonte de riqueza, o tempo de trabalho deixa e deve deixar de ser sua medida, e, portanto, o valor de troca [deve deixar de ser a medida] do valor de uso.

(Marx, 1987, p.90-91).

$O$ 'capital conhecimento’ não é capital, no sentido usual, e não tem como destinação primária a de servir à produção de sobrevalor, nem mesmo de valor, no sentido usual... Tratar o conheci-

* Doutor em Sociologia. Professor do Departamento de Sociologia da Universidade Estadual de Campinas (UNICAMP). Rua: Cora Coralina, 100, Cidade Universitária Zeferino Vaz. Cep: 13086. BarãoGeraldo,Campinas, SP.josueps@unicamp.br mento como um capital e um meio de produção é finalmente rebaixar toda atividade humana todas as capacidades cognitivas, estéticas, relacionais, corporais, etc. - a atividades instrumentais de produção, ou seja, ao produtivismo capitalista e à sua indiferença aos conteúdos.

(Gorz, 2005, p.53-58).

\section{INTRODUÇÃO}

Meu objetivo, neste artigo, é discutir a abordagem de André Gorz a respeito do trabalho imaterial, e minha principal referência é seu livro O Imaterial: conhecimento, valor e capital. Esse livro é um bom ponto de partida, primeiro, porque é inteiramente dedicado ao tema do imaterial e, segundo, porque se trata de uma crítica abrangente e profunda do capitalismo contemporâneo, cuja chave analítica encontra-se sugerida já no subtítulo.

A crítica do capitalismo é recorrente nos escritos de André Gorz desde suas primeiras publicações, o que ele faz sempre se apoiando no instrumental teórico legado por Marx. Uma vez que a perspectiva crítica e o instrumental teórico per- 
manecem constantes, é importante atentar para seus diagnósticos de época, pois são eles que realçam as eventuais mudanças sociais em curso, assim como a adequação de algumas categorias teóricas. Por isso, creio que uma boa estratégia para se apreender a tese de Gorz sobre o trabalho imaterial é partir do diagnóstico mais abrangente que ele faz do capitalismo contemporâneo, centrado numa análise imanente e articulada do que considera suas categorias centrais: conhecimento, valor e capital.

Ora, se, por um lado, essas três categorias formam o tripé de um modelo que serve para ele caracterizar o capitalismo deste início de século XXI (Gorz, 2005), por outro lado, a compreensão de seu diagnóstico fica mais evidente se o compararmos com outro modelo que caracterizaria o capitalismo do período anterior, formado, por sua vez, pelo tripé: trabalho, valor e capital (Gorz, 1968). A comparação entre os dois modelos permite evidenciar a novidade que distingue o momento atual do anterior e marca a passagem de um modelo a outro, do material ao imaterial; a novidade é a substituição de trabalho por conhecimento como força produtiva principal do capitalismo.

Pretendo, nas páginas a seguir, analisar essa mudança de trabalho para conhecimento, o que permite a Gorz contrapor o capitalismo atual, do imaterial, a outro tipo de capitalismo, que seria do material. E minha hipótese é que essa mudança está diretamente relacionada à diluição do tempo de trabalho como uma categoria central do modelo tradicional de capitalismo, assentado no tripé: trabalho, valor e capital.

\section{A DILUIÇÃO DO TEMPO DE TRABALHO}

O entendimento do trabalho como a principal força produtiva do capitalismo, como criador de valor, está no cerne da crítica da economia política elaborada por Marx (Marx, 1985). E, ainda que com variações de ênfase, esse entendimento é também partilhado por diversos autores ou mesmo correntes teóricas que, de alguma maneira, se filiam à tradição marxista. Mas o mesmo não ocor- re quando se trata do conceito de trabalho. A propósito, Gorz sugere, em um de seus livros, que o próprio Marx “já empregava a noção de 'trabalho' de forma indiferenciada colocando no mesmo plano o trabalho de um operário de fábrica e aquele do compositor ou do cientista.” (Gorz, 2003, p.132). Por essa razão, Gorz propôs, então, uma definição de trabalho que permitisse delimitá-lo claramente em relação a outras atividades:

\begin{abstract}
Definimos o trabalho no sentido econômico moderno como uma atividade desenvolvida tendo em vista a troca mercantil e que é necessariamente objeto de um cálculo contábil. O trabalhador trabalha para 'ganhar sua vida', isto é, para obter, em troca de um trabalho cujos resultados não possuem utilidade direta para ele, o necessário para comprar tudo o que precisa e que é produzido por outros que não ele. O trabalho que vende deve ser realizado o mais eficazmente possível, para poder ser trocado por quantidades iguais (e, se possível, superiores) de trabalho, incorporadas nos bens e serviços que, eles também, são produzidos o mais eficazmente possível. (Gorz, 2003, p.135-136)
\end{abstract}

Éesse trabalho-mercadoria que deve ser entendido como fonte de valorização do capital e, portanto, sua força produtiva principal. Por isso, eleétambém a base da teoria do valor de Marx. É importante, no entanto, reter algumas das características realçadas na citação acima, com destaque para "o mais eficazmente possível”, o que significa usar o tempo de trabalho como critério para medir a produtividade.

Não é, pois, por acaso, que o tempo de trabalho torna-se, então, um objeto central da reflexão de Gorz na mesma época em que se intensifica o processo de automação das atividades industriais e de serviços e o emprego da microeletrônica nessas atividades. Diferentemente de seus escritos até o início da década de 1970, quando o tema não era tão presente em suas reflexões, em seus textos do final dessa década em diante, o tempo de trabalho passou a ocupar o centro de suas preocupações. Também na virada da década de 1970 para a de 1980, sobretudo na França e na Alemanha, toma corpo um longo e intenso debate sobre a crise do trabalho e da sociedade de trabalho (Silva, 2008, p.19-33). Esse debate procurava respostas para o 
problema do desemprego, provocado pela chamada reestruturação produtiva que, em grande medida, baseava-se em tecnologias poupadoras de trabalho. E entre as respostas ao desemprego, vale destacar que a redução do tempo de trabalho aparecia como uma das principais propostas.

André Gorz foi um dos principais protagonistas desse debate, tanto por suas análises quanto por suas proposições, tratando do tema em pelo menos seis de seus livros $(1977 ; 1980 ; 1983 ; 1988$; 1991; 1997), como veremos a seguir.

Sua primeira intervenção clara no debate se deu em 1977, no livro Écologie et Liberté, no qual propunha a redução do tempo de trabalho como uma utopia possível. Como sugere o título do livro, sua proposta de redução do tempo de trabalho era parte de um projeto mais abrangente, que pode ser definido como ecossocialismo ou socialismo ecológico, ${ }^{1}$ concepção na qual se apoiava para criticar tanto o capitalismo de crescimento quanto o socialismo de crescimento: "o capitalismo de crescimento está em crise não somente porque é capitalista, mas também porque ele é de crescimento." (Gorz, 1977, p.12). ${ }^{2}$ Ele considerava, assim, que a crise do capitalismo tinha como causas o superdesenvolvimento da capacidade de produção e a destrutividade geradora de escassez, e que o desemprego, nas sociedades ditas ricas, decorria de uma redução do tempo de trabalho socialmente necessário. Por isso, ele propunha a redução do tempo de trabalho como uma alternativa não só para contornar os problemas da superprodução destruidora do ambiente natural e do desemprego, mas também porque ela, ao liberar as pessoas de parte do trabalho socialmente necessário, heterônomo, facilitaria "a expansão das atividades autogeridas e livres” (Gorz, 1977, p.94). Isso possibilitaria, enfim, um futuro no qual se pudesse "trabalhar menos, melhor e de outra forma" (1977, p.100).

Ele aprofunda essa concepção de utopia al-

${ }^{1}$ Ver a respeito, além dos livros e artigos do próprio Gorz, os seguintes estudos: Gollain (2000); Münster (2008).

2 Segundo Gorz, o mesmo valia para "o socialismo de crescimento, que a ele (capitalismo) se assemelha como um irmão, expressa a imagem deformada não de nosso futuro, mas de nosso passado." (Gorz, 1977, p.11). guns anos depois, em Adeus ao Proletariado, de 1980, livro que causou muita polêmica nos meios políticos e intelectuais de esquerda (Silva, 2011; Silva; Rodrigues, 2006). Buscando inspiração no contraponto que Marx faz entre os reinos da liberdade e da necessidade (Marx, 1985), conforme aparece no capítulo sobre a fórmula trinitária, do terceiro livro de $O$ capital, Gorz desenvolve uma concepção bidimensional de sociedade, formada pelas esferas da autonomia e da heteronomia, na qual a redução do tempo de trabalho ocupa um lugar central (Gorz, 1980). ${ }^{3}$ A compreensão dessa formulação emerge com mais clareza quando contrastada com as concepções que apareciam, por exemplo, em Estratégia operária e neocapitalismo, de 1964, quando ele defendia uma noção de autogestão baseada no controle operário da produção (Gorz, 1968). Essa última supunha a construção de um poder operário capaz de, metodicamente, por meio de uma estratégia de reformas revolucionárias, possibilitar uma reapropriação do aparato produtivo pelo proletariado. ${ }^{4}$ Durante a década de 1970, ele abandona essa ideia de apropriação coletiva, em grande medida com base na análise dos desenvolvimentos organizacionais e tecnológicos de então, conforme se pode ver no livro Adeus ao proletariado, no qual avança a tese da impossibilidade de apropriação coletiva do aparelho produtivo pelo proletariado.

Esse livro é um marco importante da reflexão mais recente de Gorz, pois representa uma ruptura com suas concepções políticas e teóricas dos anos 1960, nas quais a esperança de transformação social estava depositada no potencial revolucionário da classe operária. O livro trata de duas crises interligadas: a crise do marxismo e a crise do movimento da classe operária, ou seja, uma crise com dimensões tanto teóricas quanto empíricas: "O marxismo está em crise porque há uma crise do movimento operário" (Gorz, 1980, p.13).

${ }^{3}$ Além de Marx, Gorz refere-se explicitamente a Ivan Illich, que, no livro La convivialité, defende ideia semelhante. ${ }^{4}$ Nesse primeiro momento de sua obra, sua análise do capitalismo baseava-se no modelo: trabalho, valor e capital; e ele apostava no controle operário do processo produtivo como estratégia de transformação social (Silva, 2011). 
Ele escreveu, então, que o duplo pressuposto do socialismo científico - segundo o qual a revolução socialista seria a tarefa da classe operária, que englobaria a maioria dos produtores sociais, e a essência dessa classe seria sua consciência da impossibilidade de aceitar sua realidade social como uma classe - não se confirmou na realidade. Primeiro, afirmava ele, porque a chamada base material para o socialismo não pode ser derivada do desenvolvimento das forças de produção capitalistas, já que essas últimas só funcionam de acordo com a lógica da racionalidade capitalista; em vez de base material do socialismo, elas são na verdade um obstáculo a esse último. Em segundo lugar, também porque o desenvolvimento das forças produtivas capitalistas não funciona de maneira a permitir uma apropriação coletiva direta por parte do trabalhador coletivo, isto é, pelo proletariado.

Em Les chemins du paradis, de 1983, por outro lado, ele defenda a tese da progressiva eliminação, pela revolução microeletrônica, do trabalho que envolve um face a face do trabalhador com matéria. $\mathrm{O}$ livro é uma contribuição ao entendimento da crise contemporânea das sociedades ocidentais, à luz do que ele denomina "revolução microeletrônica", termo, aliás, já utilizado no livro anterior. Resumidamente, sua principal tese pode ser assim apresentada: a "eficácia das máquinas abolirá o trabalho, a lógica do capital e a das trocas mercantis, para fazer aparecer o 'tempo disponível' como medida da 'verdadeira riqueza'." (Gorz, 1983, p. 4).

Ao falar da revolução microeletrônica, que inauguraria a era do fim do trabalho, Gorz pondera, no entanto, que ela

[...] deve ser compreendida num duplo sentido: a) a quantidade de trabalho necessário decresce rapidamente até se tornar marginal na maior parte das produções materiais e das atividades de organização; b) o trabalho não implica mais um face a face do trabalhador com a matéria. A transformação dessa não resulta mais de uma atividade imediata completa e soberana (1983, p. 73).

Para Gorz, portanto, as mudanças levadas a efeito pela revolução microeletrônica permanecem mascaradas pela inércia de velhos conceitos, como pleno emprego, por exemplo, que continuam a esperar que o futuro nos leve de volta ao passado. Tratase de uma crítica contundente ao keynesianismo e à ideia de pleno emprego, já que, em seu entendimento, essa última não tem eficácia alguma no contexto da revolução tecnológica contemporânea. Ele conclui esse livro, formado por vinte e cinco teses, propondo, como saída para a crise de desemprego, uma política que combine uma redução geral do tempo de trabalho e a quebra do tradicional vínculo entre a renda recebida e a quantidade de trabalho executado.

Ora, esse tipo de análise, ao pôr em questão a possibilidade do poder operário na forma concebida anteriormente, contribuía também para deslocar o foco da luta por emancipação da esfera do trabalho para a do não trabalho. É daí, também, que emerge a já mencionada ideia de uma sociedade dual, assentada na contraposição entre tempo de trabalho e tempo livre, que seriam as bases, respectivamente, das esferas da heteronomia e da autonomia: "[...] só há solução dualista, pela organização de um espaço social descontínuo que comporta duas esferas distintas e uma vida ritmada pela passagem de uma à outra” (Gorz, 1980, p.116).

Gorz procura fundamentar essa solução dualista, inspirada em grande medida naquilo que Marx denominou reinos da necessidade e da liberdade, no texto a seguir:

Essa concepção dualista é, atualmente, a única realista e operacional. Porque é possível reduzir em muito o tempo de trabalho requerido de cada indivíduo para a produção do necessário; mas não é possível, em contrapartida, tornar gratificante ou liberador para aqueles que os cumprem cada um dos trabalhos socialmente necessários. É possível estender o campo das atividades autônomas, autogeridas, não mercantis, que trazem sua finalidade nelas mesmas, facilitando a autoprodução e a autoaprendizagem e substituindo pela ajuda mútua, pela cooperação e pela comunicação, uma parte dos serviços presentemente fornecidos pelas empresas comerciais ou pelas administrações; mas não é possível [...] autogerir o processo social de produção em seu conjunto nem mesmo as grandes unidades técnicas que o compõem (1980, p.118-119).

Essas ideias foram aprofundadas, sobretu- 
do, em Metamorfoses do trabalho, de 1988 (Gorz, 2003). É nas páginas desse livro que Gorz, retomando a ideia de uma utopia dualista apresentada inicialmente em 1977, desenvolve a tese da redução do tempo de trabalho como contrato social (Silva, 2011, p. 174-184).

Em Metamorfoses do trabalho, Gorz reelabora e aprofunda alguns temas presentes nos dois livros anteriores. Nesse livro, ele lida com três grandes temas inter-relacionados, que, grosso modo, coincidem com as três partes que o compõem. Mas isso não quer dizer que as três partes do livro podem ser lidas de forma independente uma da outra; ao contrário, o livro constitui-se num todo articulado, onde cada uma das partes liga-se dinamicamente às outras duas como momentos de um argumento completo. Vejamos, brevemente, de que trata cada uma delas.

A primeira parte trata do tema que dá título ao livro: metamorfoses do trabalho. Nessa parte do livro, Gorz faz um diagnóstico da sociedade contemporânea, no qual enfatiza as transformações do trabalho, ou seja, da atividade que, durante os três últimos séculos, constituiu-se no principal veículo para a integração social, sobretudo da população pobre do mundo ocidental. Apesar de a análise ter o trabalho como ponto de partida, o que, aliás, encontra justificativa na sua importância durante toda a era industrial, seu alcance é bem mais amplo que o de uma simples sociologia do trabalho. A partir de uma combinação de reconstrução histórica com reflexão teórica, Gorz consegue, nessa parte do livro, mostrar, de forma clara, que o trabalho, no sentido que o entendemos hoje, é uma invenção moderna, cuja existência coincide com o advento da industrialização capitalista. Foi esse trabalho moderno, bem tipificado pela atividade do operário industrial, do proletário de Marx, que desempenhou, durante a era moderna, o papel de "grande integrador" (Silva, 2003), de mecanismo que franqueava aos homens pobres o acesso aos direitos de cidadania. É justamente da crise desse "grande integrador" que trata essa primeira parte do livro.

A segunda parte é dedicada à "crítica da razão econômica”, expressão que serve de subtítulo ao livro. Aqui, André Gorz refina sua definição de trabalho moderno como trabalho economicamente racional como emancipação. Para Gorz, essa definição de trabalho só pode ser aplicada a atividades que combinem, ao mesmo tempo, as seguintes características: a) criam valor de uso, b) têm em vista a troca mercantil, c) são realizadas na esfera pública e d) têm o tempo como critério para medir a produtividade. Para ele, as atividades que não preenchem essas quatro condições não podem ser consideradas trabalho no sentido economicamente racional.

A maior parte das atuais atividades com fins econômicos carece, segundo Gorz, de, pelo menos, uma dessas condições que definem o trabalho economicamente racional. As atividades do biscateiro, do entregador de pizza em domicílio, da empregada doméstica, do engraxate e da prostituta, afirma Gorz, não podem ser consideradas como trabalho no sentido economicamente racional. Sua generalização, ao invés de contribuir para a emancipação da pessoa através do trabalho, ou seja, para sua integração social, contribui, na verdade, para o surgimento de um novo tipo de servidão, uma vez que o traço característico de muitas dessas ocupações é a transformação de pessoas em serviçais de outras melhor situadas no circuito da racionalidade econômica.

Gorz distingue ainda as atividades com fins mercantis daquelas atividades sem fins econômicos, sejam elas voltadas para ajudar o próximo sem expectativa de retribuição (como a dádiva), sejam aquelas voltadas para nós mesmos. Nos dois últimos casos, trata-se de atividades autônomas. Deixar a lógica da racionalidade econômica penetrar nessas últimas atividades seria correr o risco de destruição do próprio tecido social.

Após definir o trabalho economicamente racional como emancipação e delimitar as fronteiras sociais que a racionalidade econômica não poderia ultrapassar, sob pena de destruir o tecido social, ele se dedica, na terceira parte do livro, a apontar as saídas positivas que permitiriam dar sentido às transformações então em curso. Suas proposições consistiam em duas propostas articuladas. Uma política de redução programada do tem- 
po de trabalho, condição primeira para uma política de criação de empregos numa época caracterizada pela diminuição da quantidade de trabalho socialmente necessário disponível no conjunto da sociedade. A redução do tempo de trabalho permitiria uma redistribuição do trabalho existente entre as pessoas que querem trabalhar. Mas a política de redução do tempo de trabalho por ele concebida só seria possível se articulada com a implementação de uma renda de cidadania, financiada por impostos e desvinculada da quantidade de trabalho que a pessoa forneceria à sociedade. Essa última proposta complementaria a primeira e tornaria possível uma redução do tempo de trabalho sem redução de renda, deslocando o problema do financiamento da redução do tempo de trabalho da dimensão microeconômica (empresa) para a dimensão macroeconômica (conjunto da economia). A implementação dessas duas propostas criaria, ainda, condições para o surgimento e a ampliação de atividades autônomas (não mercantis), sem valor de mercado, mas de grande valor social, já que, com tempo livre e uma renda básica garantida, as pessoas poderiam dar melhor vazão à criatividade.

O conjunto da análise desenvolvida no livro constitui-se numa das críticas mais profundas e fecundas ao chamado pensamento neoliberal dominante, que prioriza os "valores" de mercado e a racionalidade capitalista. Mas não se trata, aqui, de uma crítica saudosista do tipo que postula um retorno ao pleno emprego keynesiano, pois sua percepção da dinâmica das mudanças tecnológicas em curso atualmente é de que o sentido de tais mudanças é poupar trabalho. Por isso mesmo, ela inviabiliza qualquer possibilidade de uma efetiva política de pleno emprego nos moldes tradicionais.

Gorz apostava, ao contrário, em uma saída para frente, ou seja, em propostas que permitissem traduzir as conquistas de produtividade e de economia de tempo conseguidas pela revolução tecnológica em benefício da sociedade e não apenas dos conglomerados econômicos. É esse o sentido das propostas de redução do tempo de trabalho e de renda de cidadania.

Por outro lado, uma saída para frente, no sentido proposto por Gorz, só seria possível, como fica claro ao longo de todo o livro, se fundamentada numa crítica da razão econômica. E tal crítica não se dirigia apenas aos partidários do neoliberalismo, mas também aos teóricos (e militantes) da esquerda tradicional que, a despeito de sua retórica crítica, professam a mesma crença na racionalidade econômica dos defensores da liberdade total ao mercado.

Muitos dos temas discutidos em Metamorfoses estão presentes também no livro seguinte, Capitalisme, socialisme, écologie, de 1991, uma coleção de ensaios, nos quais Gorz reafirma as principais teses dos livros anteriores, particularmente aquelas que se referem às críticas da ideologia do trabalho e da razão econômica; e à necessidade de reduzir o tempo de trabalho e de desvincular a renda do tempo de trabalho. Publicado depois da queda do Muro de Berlin e afinado com a temática ambiental, o livro procura ainda definir o que seu autor entende por socialismo nesse novo contexto; ou seja, socialismo, para ele, devia ser definido pela necessidade de alargar a esfera da autonomia individual e de impor limites à racionalidade econômica, subordinando essa última a objetivos societários (Gorz, 1991).

Por fim, conforme as palavras que escrevera num livro anterior, em circunstâncias nas quais "não são mais o trabalho e os trabalhadores, mas a vida e os cidadãos que devem ser remunerados" (Gorz, 1983, p.95), o trabalho assalariado deixa de ser a atividade principal. E isso, deve-se acrescentar, não deixa de ter implicações para a chamada lei do valor trabalho.

\section{CRISE DO VALOR E EMERGÊNCIA DO IMATERIAL}

Mas, nesse momento, sua definição de trabalho, a despeito da já anunciada crise do valor, ainda se vinculava ao tempo de trabalho como critério para medir sua produtividade; e, da mesma forma, sua concepção de uma renda cidadã também mantinha esse vínculo, razão pela qual ele não aceitava a ideia de uma transferência incondi- 
cional de renda. Uma percepção diferente a respeito da incondicionalidade da renda só aparece no livro Misérias do presente, riqueza do possível, de 1997; é também nesse livro que Gorz começa a lidar com o tema do imaterial (Gorz, 1997).

Nesse livro, Gorz discute a passagem do estado de bem estar social para o que denomina estado do capital, o problema da globalização e sua relação com a autonomização do capital e dos mercados financeiros. Também lida com a questão do trabalho, discutindo a crise da sociedade de trabalho e a metamorfose da questão salarial, além de apresentar propostas para sair da sociedade do trabalho assalariado. Em relação aos livros anteriores, a primeira novidade que aparece aqui é que seu autor passa a aceitar a ideia da renda garantida incondicional, desde que articulada, primeiro, a uma política de redistribuição do trabalho e de liberação do tempo; e, segundo, a uma política de incentivo às atividades desenvolvidas fora do mercado como, por exemplo, os círculos cooperativos. A segunda novidade, vinculada à primeira, é que, nesse livro, Gorz introduz a discussão sobre a emergência do imaterial.

Pode-se dizer que Gorz começou a elaborar sua posição a respeito da quebra de vínculo entre renda e trabalho em 1981, no texto "Nove teses para uma esquerda futura", publicado na revista Les Temps Modernes e reimpresso como prefácio à edição de bolso de Adeus ao proletariado, no mesmo ano (Gorz, 1981). Mas ele a desenvolve no livro Les Chemins du Paradis, de 1983, ${ }^{5}$ passando, desde então, a discutir o tema em diversos textos, inclusive no livro O Imaterial, onde escreve as seguintes palavras: "A renda de existência nesse contexto não serve para a atualização contínua de uma existência dependente da mercadoria, mas para a distribuição de bens que são produzíveis somente em instalações que se baseiam na divisão do trabalho por várias regiões, e sem as quais o autoabastecimento local não seria possível” (Gorz, 2005, p.76).

Embora não vinculasse a alocação de uma renda de existência ao tempo de trabalho, ele argu-

${ }^{5}$ Para uma apresentação mais completa da posição de Gorz a respeito da transferência direta de renda, ver: Silva (2010). mentava, inicialmente, que o que diferenciava os partidários de esquerda dos liberais era o fato de os primeiros defenderem a manutenção do vínculo entre renda e trabalho, de forma a conservar a relação entre direito ao trabalho e direito de cidadania; em sua visão de então, quem defendia a quebra do vínculo entre trabalho e renda era tido como liberal (Gorz, 1983, 1996; Silva, 2010). Sua mudança de posição a respeito só ocorreu no livro Misérias do presente, riqueza do futuro, de 1997. A partir de então, ele passa a defender a proposta de uma renda básica ou alocação universal incondicional; conforme suas próprias palavras: "por muito tempo, recusei a ideia de uma renda social que permita 'viver sem trabalhar'." (Gorz, 1997, p. 139).

No livro de 1997, ele afirma ter abandonado a posição anterior com base nos seguintes argumentos. Primeiro, porque "quando a inteligência e a imaginação (o intelecto geral) tornam-se a principal força produtiva, o tempo de trabalho deixa de ser a medida do trabalho; mais, ele deixa de ser mensurável". Em tais circunstâncias, “... a alocação universal e incondicional de uma renda de base, acumulável com a renda do trabalho, é [...] a melhor alavanca para redistribuir tão amplamente quanto possível, ao mesmo tempo, o trabalho remunerado e as atividades não remuneradas"(1997,p.140-141).Em segundo lugar, sea alocação de uma renda for condicionada a uma contraprestação que a justifique, essa última deve consistir em "[...] um trabalho de interesse geral na esfera pública” eque "possa ter uma remuneração por objetivo sem que esta altere seu sentido." Não sendo isso possível, a renda deve ser garantida incondicionalmente a todos, porque "só sua incondicionalidade poderá preservar a incondicionalidade das atividades que só têm sentido se forem cumpridas por elas mesmas" (p.143-144). Em terceiro lugar, ele acredita que a alocação universal é a proposta que melhor se adapta à evolução de uma economia imaterial, na qual o nível geral de conhecimento é a força produtiva principal. E, por fim, a alocação universal da renda incondicional é o que melhor responde ao impasse atual, apontando para sua superação. Portanto, sua proposição de desvincular trabalho e renda, considerada essencial para superar a crise de integração social provocada pelo desempre- 
go, está diretamenteassociada, num primeiromomento, ao debate sobre a crise do trabalho assalariado e, em seguida, à emergência da economia imaterial.

De forma geral, pode-se ver que André Gorz trata de importantes problemas contemporâneos, fazendo um diagnóstico do presente, que se constitui numa profunda crítica à atual expansão da racionalidade econômica, que procura subordinar todas as dimensões da vida humana e da sociedade à lógica da mercadoria.

Essa crítica guarda, como já foi dito antes, um forte parentesco com a crítica do capitalismo desenvolvida por Karl Marx, em quem Gorz busca grande parte de sua inspiração teórica. A propósito, o texto de Marx utilizado como epígrafe, no início deste artigo, ilustra bem esse parentesco, constituindo-se numa chave importante para os debates contemporâneos a respeito da economia e do trabalho imaterial. ${ }^{6}$ Portanto, ele serve de inspiração também para André Gorz, que desenvolve sua tese sobre o imaterial a partir de uma releitura dos Grundrisse, de Marx, de quem retoma o conceito de "general intellect". ${ }^{7}$

Isso fica evidente no livro $O$ imaterial, de 2003, onde Gorz aborda em profundidade o tema do trabalho e do capital imaterial. Vejamos, por exemplo, sua afirmação, no texto citado a seguir: a expressão ‘economia do conhecimento’, escreve ele,

${ }^{6}$ Grande parte dos estudiosos contemporâneos do imaterial recorre, de alguma forma, aos escritos de Marx, como mostram os trabalhos de Hardt e Negri (2003), Lazarato e Negri (2001), assim como autores que participam da coletânea organizada por Galvão, Silva e Cocco (2003); entre os autores brasileiros, vale destacar os seguintes: Prado (2005), Amorim (2009) e Camargo (2011). Um dos poucos autores que trataram da emergência da economia imaterial sem referência direta à obra de Marx foi Daniel Bell, que, já na década de 1970, em seu estudo sobre o advento da sociedade pós-industrial, chamava a atenção para a importância que assumia o conhecimento na nova configuração social então emergente. Bell afirmava, então, que o conhecimento teórico passava a ocupar o lugar antes ocupado pelo trabalho, derivando daí também a ideia de uma teoria do valor conhecimento, que substituiria a teoria do valor trabalho (Bell, 1976; Silva, 2008. p. 19-33).

7 "O desenvolvimento do capital fixo mostra em que medida a ciência geral da sociedade, o conhecimento, tornou-se uma força produtiva imediata e, portanto, em que medida as condições do intelecto geral são remodeladas de acordo com ele. Isso mostra em que medida as forças produtivas sociais são produzidas não meramente na forma de conhecimento, mas como órgãos imediatos da práxis social, do processo de vida real.“(Marx, 1987, p. 92).
[...] indica que o conhecimento se tornou a principal força produtiva, e que, consequentemente, os produtos da atividade social não são mais, principalmente, produto do trabalho cristalizado, mas sim do conhecimento cristalizado. Indica também que o valor de troca das mercadorias, sejam ou não materiais, não mais é determinado em última análise pela quantidade de trabalho social geral que elas contêm, mas, principalmente, pelo seu conteúdo de conhecimentos, informações, de inteligências gerais. É esta última, e não mais o trabalho social abstrato mensurável segundo um único padrão, que se torna a principal substância social comum a todas as mercadorias. É ela que se torna a principal forma do trabalho e do capital (2005, p.29).

É preciso observar, no entanto, que, na teoria de Marx, mesmo numa situação em que o trabalho imediato é considerado a principal fonte de valor, ainda assim trata-se do trabalho coletivo; ou seja, não é o trabalhador individual, mas o trabalhador coletivo que produz e adiciona valor. Por isso, a relação direta e individual de cada trabalhador com a matéria não é relevante para fundamentar a ideia de que é o trabalho vivo que produz valor. ${ }^{8}$ Se quem produz valor é o trabalhador coletivo, então essa produção de valor decorre não só do intercurso dos trabalhadores que formam esse coletivo com a natureza, mas também da interação - entre os membros - que permite formar esse coletivo. O resultado dessa interação transcende a mera soma ou adição das individualidades discretas. A base da teoria do valor não é, portanto, o trabalho concreto de cada trabalhador, individualmente, mas sim o trabalho abstrato, unificador da atividade de todos; isto é, o trabalhador coletivo.

Mas quando se fala em trabalho abstrato, está-se pensando em abstração real, com claras propriedades espaciais e temporais; não de uma mera abstração fora do tempo e do espaço. Esse

8 “No sentido econômico, o 'valor' designa sempre o valor de troca de uma mercadoria na sua relação com outras. Ele é essencialmente relativo, e não responde à pergunta: 'O que isso vale?', mas sim a: 'Quanto isso vale?'. O valor designa as diversas quantidades de diversas mercadorias pelas quais uma quantia de uma mercadoria determinada pode ser trocada. Ele designa a relação de equivalência das mercadorias, umas em relação às outras. $\mathrm{O}$ valor define cada mercadoria como permutável por todas as outras em proporções determinadas pela sua relação de equivalência. Essa relação é expressa em unidades de uma mercadoria-padrão pela qual todas as mercadorias são sempre permutáveis, e que é permutável por todas: o dinheiro" (Gorz, 2005, p. 30). 
parece ser o sentido dado por Marx ao termo “abstração real” em sua análise da forma mercadoria. Ela tem uma realidade espacial e temporal, que é a própria sociedade moderna, capitalista, cujas estruturas reificantes são abstratas, porém reais. Mas só são reais porque existem; têm, portanto, algum grau de concretude. É essa concretude que permite a Marx identificar, com certa facilidade, o trabalhador coletivo com um grupo social específico (o proletariado industrial) e atribuir a ele o estatuto de única classe produtiva ou produtora da sociedade capitalista.

Hoje, porém, a situação, pelo menos para Gorz, parece ser outra:

O conhecimento, diferentemente do trabalho social geral, é impossível de traduzir e de mensurar em unidades abstratas simples. Ele não é redutível a uma quantidade de trabalho abstrato de que ele seria o equivalente, o resultado ou produto. Ele recobre e designa uma grande diversidade de capacidades heterogêneas, ou seja, sem medida comum, entre as quais o julgamento, a intuição, o senso estético, o nível de formação e de informação, a faculdade de aprender e de se adaptar a situações imprevistas; capacidades elas mesmas operadas por atividades heterogêneas que vão do cálculo matemático à retórica e à arte de convencer o interlocutor; da pesquisa técnico-científica à invenção de normas estéticas. A heterogeneidade das atividades de trabalho ditas 'cognitivas', dos produtos imateriais que elas criam e das capacidades e saberes que elas implicam, torna imensuráveis tanto o valor das forças de trabalho quanto o dos seus produtos. As escalas de avaliação do trabalho se tornam um tecido de contradições. A impossibilidade de padronizar e estandardizar todos os parâmetros das prestações demandadas se traduz em vãs tentativas para quantificar sua dimensão qualitativa, e pela definição de normas de rendimento calculadas quase por segundo, que não dão conta da qualidade 'comunicacional' do serviço exigido por outrem (2005, p. 29).

Com isso, chegamos, portanto, a uma compreensão de capitalismo que não mais se caracteriza pelo tripé trabalho, valor e capital, mas sim pelo tripé conhecimento, valor e capital, com o conhecimento substituindo o trabalho do primeiro modelo. Nessa nova situação, a força produtiva principal não seria mais o trabalho no sentido estrito, e sim o conhecimento; não a atividade de uma classe, mas as atividades do conjunto da sociedade. Ora, com a diluição das atividades antes atribuídas a uma classe produtora, parece ocorrer uma “diluição” ou dispersão dessa classe para o conjunto da sociedade, tornando-se difícil atribuir (ou continuar atribuindo) a um grupo social específico a qualidade de único produtor de valor. Por isso, parece fazer mais sentido dizer-se que a produção de valor decorre antes do próprio processo de interação social, em suas múltiplas dimensões. Mas, se a produção de valor ocorre principalmente no processo de interação, e se esse último não pode mais ser identificado com um grupo social específico, então há uma diluição da produção de valor pelo conjunto da sociedade; ou seja, o valor é produto, sobretudo, da criatividade social.

Mas aqui parece surgir outro problema decorrente da impossibilidade de medição do trabalho:

A crise da medição do trabalho engendra inevitavelmente a crise da medição do valor. Quando o tempo socialmente necessário a uma produção se torna incerto, essa incerteza não pode deixar de repercutir sobre o valor de troca do que é produzido. O caráter cada vez mais qualitativo, cada vez menos mensurável do trabalho, põe em crise a pertinência das noções de ‘sobretrabalho' e de ‘sobrevalor'. A crise da medição do valor põe em crise a definição da essência do valor. Ela põe em crise, por consequência, o sistema das equivalências que regula as trocas comerciais (Gorz, 2005, p. 30).

Gorz afirma ainda que "o conceito de valor, no sentido econômico”, só se aplica “às mercadorias, ou seja, aos bens e serviços que foram produzidos em vista de sua troca comercial”, pois o que não é produzido com esse objetivo não tem valor no sentido econômico. É o caso das riquezas naturais - o sol, a chuva -, que não podem ser produzidos, apropriados; e dos bens comuns patrimônio cultural -, que não podem ser divididos nem trocados. ${ }^{9}$ Mas, se não podem ser apro-

9 "Essa irredutibilidade dos conhecimentos será uma fonte de dificuldades, de incoerências, de trapaças e de fantasias econômicas. O capital não pode deixar de tratar e de fazer funcionar o conhecimento como se ele fosse um capital. O problema, para o capital, é o de se apropriar, valorizar e subsumir uma força produtiva que, em si mesma, não se deixa devolver às categorias da economia política. O capital tudo fará para 'capitalizar o conhecimento', para fazê-lo corresponder às condições essenciais pelas quais o capital funciona e existe como tal, a 
priados ou valorizados, "podem ser confiscados pelo viés das barreiras artificiais”, limitando-se “o usufruto deles aos que podem pagar um direito de acesso". É por meio da "privatização das vias de acesso", de seu controle, que se transformam "as riquezas naturais e os bens comuns em quase-mercadorias", proporcionando renda e "uma forma privilegiada de capitalização das riquezas imateriais" a seus vendedores (2005, p.30-31).

Aqui, ele introduz a importante distinção entre saber e conhecimento, com base na qual pretende lidar com a questão do seu 'valor' e também mostrar os limites da eventual apropriação privada seja dos bens comuns, seja da riqueza coletivamente produzida:

Os saberes são parte integrante do patrimônio cultural, são competências comuns da vida cotidiana. É sobre essa base das competências comuns que se constroem as competências profissionais certificadas, que são produzidas em vista das trocas comerciais de serviços. Quanto aos conhecimentos, eles são o produto do 'comércio universal entre os homens', ou seja, das interações e das comunicações não comerciais [...]. Um mercado de conhecimento em que eles possam se trocar por seus ‘valores' é impensável. Não podendo se exprimir em unidades de valor, sua avaliação como capital resta problemática (Gorz, 2005, p.31).

A produção coletiva, mais simbólica que material, não se presta, no entanto, a ser apropriada pelas corporações capitalistas, a despeito dos esforços para patentear o que é criado coletivamente, tentando-se subordinar tudo à lógica do lucro capitalista:

O saber não é uma mercadoria qualquer, seu valor (monetário) é indeterminável; ele pode, uma vez que é digitalizável, se multiplicar indefinidamente e sem custos; sua propagação eleva sua fecundidade, sua privatização a reduz e contradiz sua essência. Uma autêntica economia do saber seria uma economia comunitária, na qual as categorias fundamentais da economia política perderiam seu valor e a força produtiva mais importante estaria disponível a uma tarifa zero (Gorz, 2005, p.59).

saber: o conhecimento deve economizar mais trabalho do que originalmente custou, deve submeter ao seu controle a utilização que dele é feita; e, enfim, deve-se tornar a propriedade exclusiva da firma que o valoriza incorporando-o nas mercadorias que com ele se produzem“ (Gorz, 2005, p. 31).
Daí sua preocupação em clarificar a distinção entre os conhecimentos que estão associados ao pensamento lógico e podem ser objetivados, e os saberes que estão associados à capacidade do sujeito e são, por essência, vivos e vividos:

O saber é, antes de tudo, uma capacidade prática, uma competência que não implica necessariamente conhecimentos formalizáveis, codificáveis. A maior parte dos saberes corporais escapa à possibilidade de uma formalização. Eles não são ensinados; aprendem-se-nos pela prática, pelo costume, ou seja, quando alguém se exercita fazendo aquilo que se trata de aprender a fazer. Sua transmissão consiste em apelar à capacidade do sujeito de produzir a si próprio. Isso vale tanto para os esportes quanto para as habilidades manuais e as artes. O saber é aprendido quando a pessoa o assimilou ao ponto de esquecer que teve de aprendêlo.Éa mesma coisa para as regras não escritas que regem as interações sociais e as relações entre pessoas. Assim como as regras gramaticais que presidem o funcionamento de uma língua, as regras são praticadas sem ser conhecidas, e antes de terem sido formalizadas. O que importa aqui é que o caminho do saber, saber-fazer, saber-ser, rumo ao conhecimento das leis, das regras, dos procedimentos implicados, é bem mais curto que o caminho inverso. Quem quer aprender uma língua, por exemplo, aprendendo suas regras gramaticais, não saberá falar essa língua, ao passo que aquele que em princípio treina falá-la poderá aprender mais facilmente as regras gramaticais perguntando-se sobre o funcionamento dessa língua que ele sabe, sem contudo conhecê-la (Gorz, 2005, p.32).

A partir da distinção entre conhecimento e saber, podemos perceber os traços de um eventual terceiro modelo, formado pelo tripé saber, valor e capital, em contraposição aos dois modelos anteriores: trabalho, valor e capital (primeiro modelo) e conhecimento, valor e capital (segundo modelo). Mas esse terceiro modelo, formado por saber, valor e capital, é uma impossibilidade em si porque o saber não se presta a ser a valorizado e transformado em capital no sentido econômico ${ }^{10}$; ele é, portanto, a própria negação da lógica capitalista.

\footnotetext{
10 "Os saberes comuns ativados pelo trabalho imaterial não existem senão em sua prática viva, e por ela. Eles não foram adquiridos ou produzidos em vista de trabalho que podem realizar ou do valor que podem assumir. Eles não podem ser destacados dos indivíduos sociais que os praticam, nem avaliados em equivalente monetário, nem comprados ou vendidos. Os saberes resultam da experiência comum da vida em sociedade e não podem ser legitimamente assimilados ao capital fixo. [...]
} 


\section{CONCLUSÃO}

Do que foi visto até aqui, dá para tirar algumas conclusões. A primeira delas refere-se aos modelos formados pelas categorias centrais da economia política. Em sua análise do capitalismo, conforme aparece no livro O Imaterial, Gorz toma conhecimento, valor e capital como categorias centrais e definidoras para uma economia política adequada à intelecção do capitalismo atual. Seu diagnóstico desse capitalismo, dito cognitivo, sustenta, por outro lado, que se trata de uma situação artificial, logo, insustentável. Ou seja, trata-se de um capitalismo cada vez mais propenso a crises, sobretudo porque é diferente do capitalismo clássico, assentado no tripé trabalho, valor e capital. Nesse último, o tempo de trabalho podia funcionar como critério para medir a produtividade do trabalho e dava consistência à teoria do valor, possibilitando, assim, o cálculo de equivalência nas trocas. Com a diluição do tempo de trabalho, na passagem de trabalho para conhecimento como força produtiva principal, aquela possibilidade de medir a produtividade do trabalho esvai-se, minando também a possibilidade de medida do valor e, em decorrência, o cálculo das equivalências.

Em segundo lugar, mesmo que o capital tente contornar a situação por meio da privatização dos bens naturais e comuns, controlando-lhes o acesso para mercantilizá-los, ainda assim ele não consegue fazê-lo completamente, porque nem toda atividade é passível de ser controlada e privatizada. $E$ isso vale, segundo Gorz, especialmente para os saberes, que não podem ser codificados e transformados em conhecimentos passíveis de apropriação privada por meio de patentes. Uma vez que grande parte desses saberes depende do envolvimento direto e permanente daqueles que os praticam, sua apropriação pelo capital seria impossível sem destruí-los. E destruí-los seria matar a galinha dos ovos de ouro, porque são eles que produzem a riqueza social.

Esse ‘novo capital fixo' não é trabalho acumulado, e não pode tomar a forma 'valor'. Ele é de essência social, comum a todos" (Gorz, 2005, p. 33).
Se, em terceiro lugar, são os saberes que produzem a riqueza, e ela, em razão do que foi dito até aqui, não é passível de medida e de valorização pelo critério tradicional da economia política - os tempos de trabalho gastos na produção -, então, encontramo-nos diante de uma situação na qual a própria noção de trabalho precisa ser repensada. Assim, o trabalho, entendido somente como atividades que criam valor de uso, tendo em vista a troca mercantil e realizado na esfera pública, cujo critério para medir a produtividade é o tempo - conforme aparece no livro Metamorfoses do trabalho, de 1988 - não parece ser mais capaz de dar conta do contexto do capitalismo cognitivo, em que a produção de riqueza envolve toda e qualquer atividade de interação social.

Assim, nesse novo contexto, não faz sentido considerar o trabalho, no sentido estrito de assalariamento, como critério para atribuir direitos. Daí decorre a necessidade de se desvincular renda de trabalho, transferindo-a incondicionalmente às pessoas.

Recebido para publicação em 16 de agosto de 2013 Aceito em 26 de outubro de 2013

\section{REFERÊNCIAS}

AMORIM, Henrique. Trabalho imaterial: Marx e o debate contemporâneo. São Paulo: Annablume, 2009.

GOLLAIN, Françoise. Une critique du travail: entre écologie et socialisme. Paris: Éditions La Découverte, 2000.

BELL, Daniel. The coming of post-industrial society. New York: Basic Books, 1976.

CAMARGO, Silvio. Trabalho imaterial e produção cultural: a dialética do capitalismo tardio. Sã̉o Paulo: Annablume, 2011.

GALVÃO, A.; SILVA, G.; COCCO, G (Org.) Capitalismo cognitivo: trabalho, redes e inovação. Rio de Janeiro: DP\&A, 2003.

GORZ, André. Estratégia. Operária e neocapitalismo. Rio de Janeiro: Zahar, 1968.

Écologie et liberté. Paris: Galilée, 1977.

Adieu au prolétariat. Au de-là du socialisme. Paris: Galilée, 1980 = Adeus ao proletariado. Rio de Janeiro: Forense Universitária, 1982. Versão em português.

Neuf thèses pour une gauche future. Les Temps Modernes, Paris, n.416, p.1541-1554, 1981.

Les chemins du paradis. Paris: Galilée, 1983. 
1991.

. Capitalisme, socialisme, écologie. Paris: Galilée,

Revenu de citoyenneté et pluralité des fins legitimes. Transversales, Paris, n.35, p.6-8, 1996.

Misères du présent, richesse du possible. Paris: Galilée, 1997 = Misérias do presente, riqueza do possível São Paulo: Annablume, 2004. Versão em português. $\overline{2003 .}$

. Metamorfoses do trabalho. São Paulo: Annablume,

. O imaterial. Conhecimento, valor e capital. São Paulo: Annablume, 2005.

HARDT, M.; NEGRI, A. Império. Rio de Janeiro: Record, 2003.

LAZZARATO, M.; NEGRI, A. Trabalho imaterial. Rio de Janeiro: DP\&A, 2001

MARX, Karl. O Capital. São Paulo: Nova Cultural, 1985. 3 v. Grundrisse. New York: International Publishers, 1987. (Collected works, v.29).
MÜNSTER, Arno. André Gorz ou le socialisme dificile. Clamecy,Fr: Éditions Lignes, 2008.

PRADO, Eleutério. Desmedida do valor: crítica da pósgrande indústria. São Paulo: Xamã, 2003.

SILVA. Josué Pereira da. Trabalho e integração social. In GALVÃO, A. et al. (Org.) Marxismo e ciências humanas. São Paulo: Xamã, 2003. p.269-279.

. Trabalho, cidadania e reconhecimento. São Pau1o: Annablume, 2008.

André Gorz e renda básica: uma história de conversão crítica. In: CONGRESSO BIEN, FEA - USP,13. 2010, São Paulo. 17p. 2010. Disponível em: www.sinteseeventos.com.br/bien/pt/papers/ AndreGorzeRendaBasica.pdf.

André Gorz: trabalho e política. 2.ed. São Paulo: Annablume, 2011.

RODRIGUES, Iram Jácome (Org.) André Gorz e seus críticos. São Paulo: Annablume, 2006. 


\section{LABOR TIME IN SOCIAL THEORY OF IMMATERIALITY ANDRÉ GORZ}

\author{
Josué Pereira da Silva
}

The article deals with André Gorz's formulations on immaterial labor. His analysis of contemporary capitalism is based on a model formed by the categories of knowledge, labor, and capital, being knowledge the main productive force. The article compares this model to a former one, which was made by the categories of labor, value, and capital, in which labor was the main productive force. It then stresses that the difference between them is the replacement of labor by knowledge. In a knowledge economy, as that of the first model, the productivity of activities cannot be measured by labor time as in classic capitalism; besides, most of these activities are dependent upon practical knowledge (savoir-faire) not prompted to be codified and appropriated privately. The thesis defended here is then that the main event behind this change from one model to the other is the dilution of labor time as a criterion to measure productivity; and it affects the value theory and therefore the base for calculating equivalences by capitalism. This is, according to Gorz, the main cause of the crisis of capitalism and of wage labor as the criterion for the attribution of rights; and this is also a sufficient motive for him to move in defense of unconditional income transfer to people.

KEY-wORDS: André Gorz; knowledge; immaterial labor; labor time; value theory; crisis of capitalism.

\section{TEMPS ET TRAVAIL EN THÉORIE SOCIALE DE IMMATÉRIALITÉ ANDRÉ GORZ}

\author{
Josué Pereira da Silva
}

L'article s'occupe des formulations d'André Gorz sur le travail immatériel. Leur analise du capitalisme contemporain est fondée sur um modèle formé par les catégories connaissance, valeur et capital, dans lequel connaissance est la principale force productive. Cet article compare ce modèle à un modèle anterieur, formé par les categories travail, valeur et capital, dans lequel travail était la force produtive principale; l'article mettre en relief que la différence entre les deux medèles est le remplaçement de travail par connaissance. Dans une économie de connaissance, comme laquele du premier modèle, la productivité de la majorité des activités ne peut pas être mesurée par le temps du travail comme dans le capitalisme classique; en outre, plusieurs de ces activités dépendent des savoires-faire pratiques qui ne pouvont pas être codifiés et privatisés. La thèse qui je défend ici, c'est que le principal événement de cette change d'un modèle à l'outre, c'est la dilution de temps du travail comme critère pour mésurer la productivité; et ça atteint la téorie de la valeur et, par conséquence, la base du calcul des équivalences par le capitalisme. Ça, pour Gorz, c'est la principal cause de la crise du capitalisme e du travail salarié comme moyen d'attribution des droits; et ça est aussi un motif suffisant pour lui passer à défendre l'allocation unconditionel du revenu aux personnes.

Mots-CLÉs: André Gorz; connaissance; travail immatériel; temps du travail; théorie de la valeur; crise du capitalisme.

Josué Pereira da Silva - Doutor em Sociologia. Professor do Departamento de Sociologia da Universidade Estadual de Campinas (UNICAMP). Integra o Núcleo de Pesquisa "Sociologia e Teoria Crítica, desenvolvendo pesquisas na área de Sociologia e Teoria Social Contemporâneas. Suas mais recentes publicações, são: Sociologia Crítica no Brasil (org.), 2012; André Gorz: Trabalho e Política (2ª edição), 2011; Trabalho, cidadania e reconhecimento, 2008 (para artigos e capítulos de livro, ver Lattes) 